\title{
DO PESSOAL AO POLÍTICO: AS METODOLOGIAS DE INVESTIGAÇÃO QUALITATIVA COMO ALIADAS DA AÇÃO
}

\section{Introdução}

Tem sido incómodo o persistente questionamento dos pressupostos tradicionais de produção do conhecimento científico que é feito pelos Estudos sobre as Mulheres, de Género e Feministas (EMGF) às ciências sociais e humanas. Esta visão crítica estende-se, porém, também às ciências ditas exatas, que há muito começaram a abandonar a defesa do monismo metodológico, deixando de acreditar que há apenas uma via de trabalho credível - a nomotética - para separar o domínio especulativo do científico.

Os argumentos de contestação usados pelos/as investigadores/as dos EMGF prendem-se não apenas com a conceção de sujeito (abstrato) que é objeto de estudo, mas também com a suposta neutralidade dos contextos ou, diríamos, com o quase «branqueamento» das condições de vida das pessoas, o que tornaria, nessa perspetiva, plausível aceitar a universalidade das generalizações ou validar a exaustividade inerente à noção de representatividade das amostras. Trata-se assim, de repensar criticamente as dimensões ontológicas e epistemológicas que alicerçam o trabalho de investigação, bem como as vertentes metodológicas e éticas do saber que vai sendo construído nas diversas áreas científicas.

As pesquisas de inspiração feminista desde cedo se opuseram, sobretudo depois da segunda vaga do feminismo (no final da década de 1960), aos pressupostos positivistas «tradicionais», desenvolvendo uma abordagem humanística e subjetiva por meio do uso de métodos que tornassem audível a voz das pessoas marginalizadas ou mesmo esquecidas. Nestas, incluíam-se as que faziam parte de grupos até então invisíveis (p. ex.: as mulheres em geral), mas também as que não

* Instituto Politécnico de Bragança, Centro de Investigação em Educação de Adultos e Intervenção Comunitária (CEAD), Universidade do Algarve, Portugal.

Endereço postal: Campus de Santa Apolónia, 5301-856 Bragança, Portugal.

Endereço eletrónico: sbergano@ipb.pt

ORCID: https://orcid.org/0000-0002-9523-8884

** Faculdade de Psicologia e de Ciências da Educação, Universidade de Coimbra, Centro de Investigação em Educação de Adultos e Intervenção Comunitária (CEAD), Universidade do Algarve, Portugal.

Endereço postal: Rua do Colégio Novo, 3001-802, Coimbra, Portugal.

Endereço eletrónico: vieira@fpce.uc.pt

ORCID: https://orcid.org/0000-0002-9814-1076 
dominavam as ferramentas linguísticas e a tecnicidade dos instrumentos de produção da informação, sendo em consequência disso subestimadas na sua capacidade de dar significado ao mundo em que viviam.

Na psicologia, Carol Gilligan ([1982] 1997) veio a público, num livro publicado no início da década de 1980, com o título original In a different voice ${ }^{1}$, denunciar o facto de o seu colega Lawrence Kohlberg se ter esquecido de metade da humanidade, uma vez que propôs uma teoria do desenvolvimento do juízo moral - com uma universalidade na sequência das fases - baseada no estudo de 84 rapazes que acompanhou durante 20 anos. Nessa mesma obra, a autora relembra ainda os estudos de Jean Piaget, sobre o mesmo tema, no qual «as raparigas ficam de lado, como uma curiosidade à qual ele dedica quatro curtas referências num índice que omite «rapazes» porque a «criança» é assumida como masculina» (Gilligan [1982] 1997, 35). Talvez por isso se compreenda por que razão a «natureza e o significado do desenvolvimento das mulheres foram obscurecidos e envolvidos em mistérios durante tanto tempo» $(1997,35)$.

No domínio da sociologia, ouviu-se a crítica ao chamado malestream, que denotava a exclusão da vida das mulheres do foco das investigações, por serem consideradas secundárias ou sem importância. Para Dorothy Smith (1987), o feminismo deu às mulheres o direito de ver os seus interesses representados naquela área do saber, «em vez de aceitarem como autoridade os interesses de uma sociologia desenvolvida por homens» $(1987,85)$.

Experiências de observação participante em contextos de ruralidade em Portugal a meio da década de 1980 mostraram, por exemplo, que as pessoas não respondiam às questões colocadas pelo investigador porque não sabiam responder; os seus quadros de referência eram simplesmente diferentes daqueles de quem tinha concebido a pesquisa (Portela 1985). Não se tratava, por isso, de uma intenção explícita de ocultação da informação, mas eram elas - as pessoas que viviam numa aldeia do interior pobre do país - que tinham a perspetiva émica ${ }^{2}$ (linguagem de primeira ordem) que o investigador em causa pretendia compreender e comunicar à comunidade científica, através da perspetiva ética, isto é, de uma linguagem de segunda ordem, de teor formal e erudito.

São vários os/as autores/as (e.g., Olesen 2005; Denzin e Lincoln 2011; Mills e Birks 2014) que, ao descreverem o percurso histórico de desenvolvimento da investigação qualitativa, dão conta desta sua relação com crescente estatuto epistemológico dos EMGF como área interdisciplinar ${ }^{3}$. Parece, pois, consensual que o

A obra foi traduzida para português e publicada em 1997, pela Fundação Calouste Gulbenkian, com o título Teoria Psicológica e Desenvolvimento da Mulher.

Os termos emic e etic foram propostos pelo antropólogo americano Kenneth Pike, em 1954, no âmbito dos seus estudos no campo da antropologia cultural (Keating 2001).

Ver a este propósito uma Carta escrita por sete investigadoras e um investigador dos EMGF da Academia portuguesa às Secretárias de Estado do Ensino Superior, Ciência e Tecnologia e da Cidadania e Igualdade, em 2017, no qual foram expostos fundamentos e reivindicadas medidas 
feminismo exerceu um papel fundamental no campo da metodologia da investigação científica, por «honrar as vozes mudas» (Reason 1994a, 33). Veio, pois, tentar quebrar uma tendência, sobretudo ocidental, de representar o mundo através de uma ciência masculina, branca, de cunho patriarcal, onde as mulheres sempre tiveram consciência da importância da sua participação, sofrendo no entanto o abafamento da sua voz (Reason 1994b).

Por influência dos feminismos, a defesa de que o «pessoal é político» ${ }^{4}$ levou a comunidade científica, por exemplo, na área dos estudos culturais, a reconhecer o ato de fazer ciência como intencionalmente politizado, já que as experiências vividas das pessoas só ganhavam significado se perscrutadas através de dimensões pessoais de quem era objeto de estudo. Não é por isso possível manter a neutralidade no ato de investigar fenómenos humanos, onde a dimensão da alteridade na relação estabelecida entre quem investiga e quem participas na investigação tem inerentemente subjetividade, a qual deve ser reconhecida como lente indispensável de análise e de interpretação do que se estuda.

\section{Sobre a influência do pensamento feminista na investigação qualitativa}

A investigação qualitativa é diversa, quer no que diz respeito aos seus fundamentos filosóficos e epistemológicos, quer do ponto de vista metodológico e axiológico. De acordo com Denzin e Lincoln (2011), a definição do campo da metodologia qualitativa tem de considerar a pluralidade teórica a que se associa como o construtivismo, a teoria crítica, o feminismo, os estudos queer, as teorias da raça, os estudos culturais, entre muitas outras propostas. Da mesma forma, observase uma diversidade de métodos e estratégias de investigação, como o estudo de caso, a etnografia, as histórias de vida, a análise documental, a observação participante, etc. São também múltiplas as áreas disciplinares em que é utilizada e para as quais tem contribuído, o que ilustra bem o seu potencial para construir um conhecimento que permite apreender a dinâmica e complexidade das vivências humanas. Este aspeto revela uma das características fundamentais da investigação qualitativa (Bergano e Vieira 2016): o seu foco na experiência humana, através de uma abordagem holística das questões, que permite descrever e interpretar a complexidade dos fenómenos sociais, tornando visível e respeitando a unicidade das pessoas e grupos a partir dos quais, e com os quais, se constrói o conhecimento.

de política para a ciência, tendo em vista Reforçar o Sucesso e a Excelência dos Estudos de Género em Portugal. Disponível em <https://apem-estudos.org/pt/files/2017-08/recomenda-es-para-odesenvolvimento-dos-emgf-30junho2017.pdf>.

4 De acordo com van Loon, este slogan famoso dos movimentos feministas dos anos 1970 «pode ser considerado como a definição perfeita da abordagem dos estudos culturais às "experiências vividas"»» $(2001,277)$ das pessoas estudadas. 
A este respeito, Olesen destaca como características comuns aos estudos feministas e aos estudos qualitativos a diversidade, a controvérsia, a dinâmica e o seu caráter desafiante. Dentre esta diversidade destaca, no entanto, que um dos temas dominantes na investigação qualitativa de influência feminista é a questão do conhecimento, designadamente, no que se refere às interrogações que suscita, nomeadamente, de quem é o conhecimento, onde e como foi obtido, por quem, a partir de quem, e com que propósito? $(2011,129)$. Estas indagações estão relacionadas com os processos de produção do conhecimento, com as relações entre intervenientes neste processo e também com a pertinência social do saber produzido. Articulam especificidades epistemológicas, ontológicas éticas e políticas, o que de resto é reconhecido e sublinhado por Rogowska-Stangret (2018), a respeito do «conhecimento situado» proposto por Haraway (1988) no final da década de 1980. A importância deste conceito foca-se na tentativa de ultrapassar a dualidade entre objetividade e relativismo, uma vez que, segundo a autora, os polos desta díade, ainda que aparentemente opostos, são semelhantes no que toca à impossibilidade de «ver» a realidade com clareza (Haraway 1988, 584). Assim, pensar fora desta dualidade permite um conhecimento assente «numa objetividade que privilegie a contestação, a desconstrução, a construção apaixonada, as conexões intrincadas, e a esperança de transformação de dois sistemas de conhecimento e das formas de ver» $(1988,585)$. Como se pode verificar, estamos perante a proposta e a possibilidade de compreender que o conhecimento científico deve afastar-se da suposta neutralidade de uma "ciência asséptica» (Alvarez, Vieira, e Ostrouch-Kamińska $2017,17)$ sem comprometer os requisitos de rigor conceptual, metodológico e ético dos quais não se pode distanciar.

Na dinâmica de produzir conhecimento e de pensar crítica e reflexivamente sobre o conhecimento produzido, as inter-relações entre estes processos têm contribuído para o desenvolvimento de um saber fundado e fundamentado no reconhecimento do outro, da sua especificidade e da sua unicidade. Esta análise focada na diversidade das pessoas, das suas vivências e dos seus contextos, dá visibilidade ao particular, ao contextual e ao idiossincrático, isto é, ao que as investigações quantitativas têm negligenciado em nome da necessidade de generalização (caráter nomotético) e da (suposta) neutralidade da ciência.

A investigação qualitativa pressupõe uma aproximação a uma interpretação do conhecimento científico como um saber que se pretende mais democrático e transformador, que participa na construção e consolidação de uma sociedade mais justa, equitativa e sustentável. É, por esse motivo, um conhecimento que resultou de um processo coconstruído, que ativou e mobilizou todas as partes envolvidas na sua produção, que pretende informar e esclarecer a opinião pública, e que almeja fundamentar a ação (política ou de outra natureza).

Esta forma de interpretar a função social do conhecimento tem assumido, nos EMGF, uma importância fundamental, uma vez que tem tornado visíveis situações de iniquidade que habitam e limitam os quotidianos de muitas mulheres e 
também de muitos homens. A este respeito, Fonseca, Araújo e Magalhães (2000) referem a existência de um forte movimento em defesa das metodologias qualitativas protagonizado por investigadoras feministas, uma vez que este tipo de investigação permite aceder às experiências das mulheres, dando-lhes voz, e possibilita também convocar as suas subjetividades, o que viabiliza a produção de uma ciência mais humana e sensível à vida das pessoas (Vieira 2019), às suas experiências e às interpretações que fazem das suas vivências, das suas relações com outras pessoas e com as instituições.

\section{A produção de conhecimento como processo partilhado}

O processo de questionamento sobre o conhecimento e as relações que a sua produção e difusão envolvem é comum à investigação qualitativa e aos EMGF, como se disse atrás. E esta postura crítica é também visível no processo de produção de conhecimento, o que se concretiza numa outra forma (que não a tradicional) de compreender a relação entre quem desenvolve as investigações e as pessoas que nelas estão envolvidas. Estas últimas veem reforçada a sua identidade de sujeitos que participam na investigação, libertando-se da sua situação de objetos sobre os quais o ato de conhecer se desenvolve.

A investigação qualitativa propõe uma outra forma de analisar a realidade, valorizando a complexidade e a dinâmica dos contextos sociais e focando o interesse da ciência nas vivências das pessoas (Bergano 2012). Como já foi referido, a complexidade das questões inerentes às diferentes formas de discriminação de género (ou outras), e a inevitabilidade de uma análise interseccional dos diferentes eixos de privilégio e de opressão, que este campo do saber visibiliza, exige a articulação de perspetivas teóricas holísticas com metodologias de investigação que deem conta dessa integralidade das pessoas e das suas vivências. Quando este pressuposto se torna matricial, o sujeito, que, nas perspetivas mais tradicionais de investigação, é visto como objeto de estudo, adquire um novo estatuto epistemológico (Amado 2014) e passa a ser conceptualizado como participante na/da investigação. À medida que se dá voz às pessoas, a investigação deixa de ser sobre elas e passa a ser investigação com elas (Vieira 2004). As pessoas são convidadas a interpretar-se e a interpretar o mundo, e desta forma a pesquisa torna-se um processo de reflexibilidade dialética entre quem investiga e quem participa na investigação. $\mathrm{O}$ conhecimento produzido neste processo transporta o compromisso da partilha que lhe deu origem, o que pressupõe a sua devolução ao contexto em que colaborativamente se construiu. É assim um conhecimento cuja credibilidade científica é resultante do seu valor para a intervenção, seja para tornar visíveis e resolver problemáticas específicas de pessoas e grupos, seja para melhorar a vida coletiva comum. 


\section{Um saber socialmente justo e comprometido com os direitos das pessoas}

A ciência e a produção de conhecimento científico devem assumir o compromisso ético da inclusão e, para cumprirem tal desígnio, é necessário que sejam metodologicamente diversas (Alvarez, Vieira, e Ostrouch-Kamińska 2017). Se, por um lado, a investigação tradicional de cariz positivista valoriza a representatividade e a generalização, por outro lado, exclui do seu foco de interesse todas as pessoas (mulheres e homens) que, por pertencerem a grupos minoritários, veem as suas especificidades e idiossincrasias ocultadas por esta forma de fazer ciência. Neste sentido, através da afirmação e desenvolvimento dos paradigmas interpretativo e crítico, resgatou-se um conjunto de questões e experiências de vida que, por serem muito particulares de grupos de pessoas específicos, exigem abordagens investigativas holísticas, contextuais e críticas, que permitam uma outra apropriação da realidade.

Um contributo fundamental para compreender a importância de analisar as especificidades das pessoas tem sido a perspetiva de Butler (1990), que, ao aprofundar o conceito de género, coloca em causa a homogeneidade das categorias homem e mulher e questiona a visão dualista em que tradicionalmente emergiam estas questões, sublinhando que tratar todas as mulheres (ou todos os homens) como se fossem iguais está na base de múltiplas invisibilidades e discriminações, sofridas por mulheres e também por homens.

Ainda sobre as questões éticas associadas à investigação qualitativa relembramos a imersão na complexidade da relação dialética entre o sujeito enquanto ser individual e o contexto em que se desenvolve e no qual participa. Este princípio convoca a utilização de metodologias de forte inspiração fenomenológica e hermenêutica que, quando perspetivam a realidade social como dinâmica e coconstruída pelos sujeitos, exigem que investigar seja um processo que parte da vida das pessoas, das interpretações que fazem das suas circunstâncias, das justificações que utilizam para legitimar as suas escolhas e dos recursos culturais de que dispõem para construir as narrativas que dão sentido às suas vidas (Bergano e Vieira 2016). E, por tudo isto, torna-se fundamental o respeito profundo pela pessoa e pelo seu contexto. Passa-se, assim, do pessoal ao político - para retomar o mote dos movimentos feministas de segunda vaga que se escolheu para o título - ao trazer para o domínio da investigação problemáticas muitas vezes privadas e invisíveis ao escrutínio público, mas cuja resolução é um imperativo para o empoderamento das pessoas e para a garantia da dignidade das suas vidas. Sem essa intencionalidade, acrescida de preocupações com o respeito pela ética do ato nobre de investigar e com o rigor na difusão do saber produzido, incluindo a relação entre pares na comunidade científica, não vale a pena fazer ciência.

O presente dossier temático - Epistemologias, metodologias e produção de conhecimento crítico de matriz qualitativa em Estudos sobre as Mulheres, de Género e Feministas - propõe um conjunto de textos que ilustram a diversidade metodológica que 
caracteriza a investigação qualitativa e o seu potencial na construção de um conhecimento que se enraíza nas vivências das pessoas, que lhes dá voz e que permite compreender a complexidade das suas experiências de vida em discurso direto.

O primeiro texto do dossier - Construção do pânico moral a partir das questões de gênero e sexualidades nos discursos ultraconservadores no Brasil -, da autoria de Cleide Ester de Oliveira, Nadir de Fátima B. Bittencourt, Veralúcia G. de Souza, Paulo Sesar Pimentel, Kátia Terezinha P. Ormond e Isabel Cristina Silva, aborda a perigosa discursividade de líderes políticos e religiosos brasileiros a respeito do modo como ideologicamente interpretam o conceito de género e o ligam às sexualidades. Sublinha, ainda, a forma como esta discursividade contribuiu para induzir o «pânico moral» na sociedade, através da reprodução desses discursos e da difusão do preconceito em relação aos direitos das pessoas LGBT e à promoção da igualdade de género. Para abordar esta questão, são mobilizadas as contribuições teóricas da arqueogenealogia de Foucault. As categorias abordadas na análise do discurso são: discurso, poder/saber/verdade e normatização, através das quais são analisados vídeos do YouTube de acesso aberto. Deste texto, destaca-se a análise de como o poder se manifesta no discurso e como, através dele, se distorcem propositadamente propostas teóricas sobre o género e se difundem cosmovisões assentes numa perspetiva heteronormativa da sexualidade e de rejeição dos direitos das pessoas que dela são excluídas. Um outro aspeto que importa realçar neste trabalho é a descrição dos mecanismos de articulação entre o discurso e o poder, pelos quais se difunde o ideário ultraconservador que reproduz o preconceito e a violência sobre as pessoas LGBT no Brasil nos dias de hoje.

O segundo texto do dossier - Violación de adolescentes en situación de calle en Medellín, Colombia -, de Anghie Phamela López Mejía, Constanza Forero Pulido e Álvaro Giraldo Pineda, aborda a situação de crianças e jovens que vivem na rua por terem sido vítimas de violência sexual nos seus contextos familiares, mais especificamente de jovens raparigas com idades entre os 12 e os 18 anos que vivem nas ruas de Medellín. A investigação apresentada recorre à etnografia e tem como principais estratégias de recolha de dados a entrevista em profundidade e os diários de campo produzidos pelos/as investigadores/as. Com esta aproximação metodológica, é dada primazia à voz das jovens que constituem o grupo de participantes da investigação, dando visibilidade à violência a que estiveram sujeitas (em contexto familiar) e à sua situação de vulnerabilidade atual, na rua, que as expõe a formas acrescidas de violência sexual e física. Neste sentido, o estudo descrito é um exemplo de como as abordagens centradas nas pessoas e nas suas vivências podem contribuir para a compreensão dos fenómenos sociais marcados pela complexidade e também para a intervenção mais informada e fundamentada, no âmbito do apoio social e de saúde prestado a estas populações. Destaca-se ainda de forma muito cruel a certeza de que, em muitos casos, a família não é um lugar seguro para as mulheres, qualquer que seja a sua idade. 
O texto de Daniela Garcia Damaceno, Miriam Fernanda Sanches Alarcon, Viviane Boacnin Yoneda Sponchiado, Mara Quaglio Chirelli, Maria José Sanches Marin e Joyce Fernanda Soares Albino Ghezzi - com o título Mulheres idosas vítimas de violência: o protagonismo nas denúncias - foca também a violência sobre mulheres em contexto familiar que, neste caso, foram capazes de fazer a denúncia já em idades avançadas. A entrevista a mulheres idosas vítimas de violência foi a estratégia de recolha de dados utilizada neste trabalho, e a informação recolhida foi tratada com recurso à análise temática de conteúdo. Dos resultados ressalta a ambivalência sentida por estas mulheres, que, por um lado, se sentem empoderadas por terem feito a denúncia da violência de que foram alvo e, por outro, se sentem angustiadas pelos sentimentos que as ligam aos agressores. Também neste trabalho se parte da experiência das mulheres e das suas vozes, o que permite identificar aspetos que favorecem as denúncias de violência e a agência das vítimas, como, por exemplo, o apoio social de que usufruem. De forma contrária, são nomeados fatores que perpetuam a situação de violência, como a manutenção de modelos do que é «ser mulher», associados aos papéis sociais de mães, esposas e cuidadoras, os quais contribuem para a reprodução de comportamentos ensinados que podem desencadear a interpretação da denúncia como a não assunção de um desse papéis. Mais uma vez se evidencia a relevância de ouvir o discurso das mulheres, que falam das suas angústias e dos seus recursos reais e simbólicos, para fundamentar a intervenção em casos concretos e a prevenção de potenciais situações diversas de vulnerabilidade.

Struggling for the dignity of women with Relapsing-Remitting Multiple Sclerosis: An interpretative phenomenological single case study analysis, de Michaela Miertová, Juraj Čáp e Katarína Žiaková, é o quarto texto apresentado neste dossier. Tratase de um estudo de caso único de inspiração fenomenológica interpretativa, com recurso à entrevista, cujo objetivo foi explorar o significado da dignidade de uma mulher com esclerose múltipla recidivante remitente. Neste artigo, sublinha-se a relevância de compreender a questão da dignidade a partir do ponto de vista de uma mulher numa condição marcada por uma enorme especificidade. Este trabalho constitui um contributo extraordinário para a formação de profissionais que prestam cuidados de proximidade. As conclusões retiradas deste estudo de caso têm implicações profundas para a reflexão em torno da humanização dos cuidados de saúde e dos serviços de apoio social prestados a pessoas com doenças crónicas, especialmente porque se focaliza na necessidade de perceber as questões da dignidade a partir da própria pessoa e da leitura e interpretação que ela faz da situação em que se encontra.

Os dois últimos textos que constituem o dossier são também do âmbito da saúde e referem-se a temas relacionados com a gravidez, a saber: Maternidade Tardia: da consciencialização do desejo à decisão de ser mãe, de Maria Anabela Ferreira dos Santos, Maria dos Anjos Pereira Lopes e Maria Antónia Rebelo Botelho; e Perspectivas y experiencias sobre el consumo de bebidas alcohólicas durante el embarazo: estu- 
dio cualitativo con embarazadas de España, Francia y Portugal, da autoria de Renata Franco, Belén Charro e Maria Raul Xavier.

No primeiro destes textos, as autoras recorrem à Grounded Theory como metodologia de investigação e utilizam a entrevista semiestruturada, o Photovoice e notas de campo como estratégias de recolha de dados. O recurso à Grounded Theory torna necessária a explicitação das representações de quem investiga sobre o que é investigado e atribui ao conhecimento produzido um estatuto diferenciado (quando comparado com o que resulta de outros processos de investigação). Assim, as conclusões de quem faz investigação não são entendidas como representativas de uma verdade, ou de uma realidade descoberta, mas têm e assumem o estatuto de conjunto de interpretações de múltiplas realidades que foram mutuamente construídas pelas investigadoras e pelas participantes.

No último artigo do dossier, o objetivo do trabalho de investigação apresentado consistiu em explorar perspetivas e experiências de grávidas espanholas, francesas e portuguesas quanto ao consumo de álcool durante a gravidez. Para o efeito, as autoras desenvolveram um estudo qualitativo baseado numa abordagem fenomenológica, no qual foram realizadas 68 entrevistas. A análise dos dados foi feita com recurso ao programa QSR-NVIVO. Dos resultados obtidos, destacam-se semelhanças nas perceções sobre os efeitos do consumo de álcool durante a gravidez nos três países analisados e a existência de informação limitada e/ou errada quanto às consequências da exposição pré-natal a estes consumos por parte das gestantes.

As autoras e os autores que contribuíram para este dossier da ex æquo são de oito nacionalidades diferentes, mas têm em comum o reconhecimento do valor da investigação qualitativa para a construção de um conhecimento cientificamente válido, em diversas áreas, que seja também rigoroso do ponto de vista metodológico e valioso para a intervenção, cumprindo todos os requisitos éticos.

Agradecimentos: Este trabalho é financiado por Fundos Nacionais através da FCT - Fundação para a Ciência e a Tecnologia, no âmbito do Projeto UIDB/05739/2020.

\section{Referências bibliográficas}

Alvarez, Teresa, Cristina Vieira, e Joanna Ostrouch-Kamińska. 2017. «Género, educação e cidadania: que «agenda» para a investigação científica e para o ensino e a formação.» ex æquo, 36: 9-22. DOI: https://doi.org/10.22355/exaequo.2017.36.01

Amado, João. 2014. Manual de Investigação Qualitativa em Educação. 1. ${ }^{a}$ ed. Coimbra: Imprensa da Universidade de Coimbra.

Bergano, Sofia. 2012. «Ser e tornar-se mulher - Classe Social, educação e discursos sobre identidade(s) feminina(s).» Tese de Doutoramento em Ciências da Educação (não publicada). Universidade de Coimbra. 
Bergano, Sofia, e Cristina C. Vieira. 2016. «Dar visibilidade científica a assuntos na sombra: contribuições mútuas entre os estudos de género e a investigação qualitativa.» Atas CIAIQ 2016 - Investigação qualitativa em ciências Sociais 3: 508-518. Disponível em https://proceedings.ciaiq.org/index.php/ciaiq2016/article/view/995

Butler, Judith. 1990. Gender Trouble: Feminism and the Subversion of Identity. New York: Routledge.

Denzin, Norman, e Yvonna Lincoln. 2011. «Introduction: the discipline and practice of qualitative research.» In The Sage Handbook of Qualitative Research. 4. ${ }^{a}$ ed., editado por Norman Denzin e Yvonna Lincoln, 1-19. Thousand Oaks, CA: Sage Publications.

Fonseca, Laura, Helena Araújo, e Maria José Magalhães. 2000. «Integrando as metodologias qualitativas na sua contribuição para o campo educativo e de estudos sobre as mulheres.» In Actas do Seminário Internacional Coeducar para uma sociedade inclusiva, 133-146. Lisboa: CIDM.

Gilligan, Carol. (1982) 1997. Teoria Psicológica e Desenvolvimento da Mulher, traduzido por Natércia Rocha. Lisboa: Fundação Calouste Gulbenkian.

Haraway, Donna. 1988. «Situated Knowledges: The Science Question in Feminism and Privilege of Partial Perspective.» Feminist Studies 14 (3): 575-599. DOI: https://doi. org $/ 10.2307 / 3178066$

Keating, Elizabeth. 2001. «The Ethnography of Communication.» In Handbook of Ethnography, editado por Paul Atkinson, Amanda Coffey, Sara Delamont e Lyn Lofland, 285301. London: Sage Publications.

Mills, Jane, e Melanie Birks. 2014. «Introducing Qualitative Research.» In Qualitative Methodology: a practical guide, editado por Jane Mills e Melanie Birks, 3-15. London: Sage Publications.

Olesen, Virginia. 2005. «Early Millennial Feminist Qualitative Research: Challenges and Contours.» In The Sage Handbook of Qualitative Research. 3. ${ }^{\text {a }}$ ed., editado por Norman Denzin e Yvonna Lincoln, 235-278. London: Sage Publications.

Olesen, Virginia. 2011. «Feminist Qualitative Research in the Millennium's first Decade.»In The Sage Handbook of Qualitative Research. 4. ${ }^{a}$ ed., editado por Norman Denzin e Yvonna Lincoln, 129-146. Thousand Oaks, CA: Sage Publications.

Portela, José. 1985. «Observação Participante (Reflexões sobre uma Experiência).» Cadernos de Ciências Sociais 13: 157-176.

Reason, Peter. 1994a. «Future Participation.» In Participation in Human Inquiry, editado por Peter Reason, 30-39. London, Sage Publications.

Reason, Peter. 1994b. «Participation in the Evolution of Consciousness.» In Participation in Human Inquiry, editado por Peter Reason, 16-29. London, Sage Publications.

Rogowska-Stangret. Monika. 2018. «Situated Knowledges.» NewMaterialism.eu. Disponível em https://newmaterialism.eu/almanac/s/situated-knowledges.html (Consultado em 30 de maio de 2020).

Smith, Dorothy. 1987. Women's Perspective as a Radical Critique of Sociology. In Feminism and Social Theory, editado por S. Harding. Milton Keynes: Open University Press, 84-96.

van Loon, Joost. 2001. «Ethnography: A Critical turn in Cultural Studies.» In Handbook of Ethnography, editado por Paul Atkinson, Amanda Coffey, Sara Delamont e Lyn Lofland, 273-284. London: Sage Publications.

Vieira, Cristina C. 2004. "A investigação participativa: Algumas considerações em torno desta metodologia qualitativa.» In Investigação em educação. Abordagens conceptuais e práticas, organizado por Lúcia Oliveira, Anabela Pereira e Rui Santiago, 59-76. Porto: Porto Editora. 
Vieira, Cristina C. 2019. «Investigação, conhecimento científico e responsabilidade social: reflexões a partir das Ciências Sociais e Humanas.» Exedra, Número Temático EIPE 2019: 28-37. Disponível em http://exedra.esec.pt/wp-content/uploads/2020/01/ 03-EIPE2019.pdf

Sofia Bergano. Professora Adjunta do Departamento de Ciências da Educação e Supervisão da Escola Superior de Educação do Instituto Politécnico de Bragança, doutorada em e Ciências da Educação, especialização em Educação Permanente e Formação de Adultos, na Faculdade de Psicologia e de Ciências da Educação da Universidade de Coimbra. Membro integrado do Centro de Investigação em Educação de Adultos e Intervenção Comunitária (CEAD), da Universidade do Algarve.

Endereço eletrónico: sbergano@ipb.pt

Cristina C. Vieira. Professora Associada da Faculdade de Psicologia e de Ciências da Educação da Universidade de Coimbra. Membro integrado do Centro de Investigação em Educação de Adultos e Intervenção Comunitária (CEAD). Tem ampla experiência de docência em cursos de licenciatura, mestrado e doutoramento, na área das metodologias quantitativas e qualitativas de investigação em ciências sociais e humanas. Codiretora da Rede de Género e Educação de Adultos da ESREA. Colabora com regularidade com a FCT na avaliação de projetos, relatórios e candidaturas a bolsas de investigação.

Endereço eletrónico: vieira@fpce.uc.pt 